\title{
Complex Approach to the Development of Potash, Potassium-Magnesium and Salt Deposits
}

\author{
Nikita Lipnitsky ${ }^{1, *}$, and Yana Kuskova ${ }^{2}$ \\ ${ }^{1}$ LLC SPb-Giproshakht, 197101, 15A Chapaeva st., Saint Petersbourgh, Russian Federation \\ ${ }^{2}$ Saint-Petersburg Mining University, 21 Line, 2, St. Petersburg, 199106, Russian Federation
}

\begin{abstract}
Salt minerals of various deposits belong to the sedimentary rocks class. They were formed with the long evaporation of seawater in different geological epochs and therefore consist, as a rule, of salt minerals belonging to chlorides and sulphide of alkali and alkaline-earth metals. For example, the Starobinsky deposit is characterized by halogen compounds, and Kalushsky and Stebnikovskoye ones by sulfate salts. In addition, in Berezniki deposit and in other Russian deposits there are mixed rocks, including various potassium compounds. Taking into account the peculiarities of potash deposits caused by their easy solubility, a comprehensive solution for their development, containing both the conditions for conducting mining operations and the conditions for the enrichment of potassium-bearing ores, will be relevant.
\end{abstract}

\section{Introduction}

The main chloride minerals found in the above deposits are: halite, silvin, sylvinite and carnalite, and cainite, including magnesium sulfate.

Galite is a mineral of chlorides subclass, a crystalline form of sodium chloride $(\mathrm{NaCl})$. Raw materials from which the salt and technical salt is made.

Silvin is a mineral from the class of halides, the chemical composition of $\mathrm{KCl}$; contains $52.48 \% \mathrm{~K}$, as well as impurities $\mathrm{Br}$, less often I. Incorporated gas bubbles (N2, CO2, CH4, $\mathrm{He}$, etc.) impart a milky white color to transparent and colorless sylvite crystals. It also contains halite $(\mathrm{NaCI})$ and iron oxide $\mathrm{Fe} 2 \mathrm{O} 3$ in the form of impurities which gives the mineral a red color.

Silvinit is a mineral consisting of alternating layers of halite and sylvite $(\mathrm{nNaCl}+$ $\mathrm{mKCl}$ ) and some impurities (hematite, etc.). The ratio between potassium chloride and sodium in sylvite is not constant. It usually contains a little sand, clay, gypsum, etc. in the form of impurities. It has a heterogeneous color - there are red, pink, blue and orange crystals. It is almost completely soluble in water (except impurities).

Carnallite is a mineral from the group of double chloride salts. The composition of carnallite is $\mathrm{KCl} \cdot \mathrm{MgCl} 2.6 \mathrm{H} 2 \mathrm{O}: \mathrm{Mg}$ is $8.7 \%, \mathrm{~K}$ is $14.1 \%, \mathrm{Cl}$ is $38.3 \%$, and water $(\mathrm{H} 2 \mathrm{O})$ is $38.9 \%$. A specific feature of carnallite is a burning salty taste, it is highly hygroscopic.

\footnotetext{
* Corresponding author: lipnickii.nikita@mail.ru
} 
Cainite is a special mineral of the sulfate class containing potassium chloride and magnesium sulfate, of the composition $\mathrm{KMg}(\mathrm{SO} 4) \mathrm{Cl} 3 \mathrm{H} 2 \mathrm{O}$. It is a light grainy mass [1].

The value of potassium in the human body cannot be overestimated: its content is about $2000 \mathrm{mg} / \mathrm{kg}$. Functions of potassium in the body are diverse: maintaining the water balance and acid-base balance; regulation of blood pressure and normalization of rhythms of the heart muscle; stimulation of activity of neuromuscular cells; regulation of the activity of enzymes associated with the transformation of carbohydrates and proteins. The mandatory daily dose of potassium is 2-4 grams, and the main source for it is vegetables. Vegetable crops have a carbohydrate type of metabolism, so they take more potassium than other elements.

Potassium fertilizers increase the dry matter, sugars and vitamin $\mathrm{C}$ content in cabbage, carotene in carrot roots, and, especially potassium chloride reduce nitrate content in vegetable products.

The use of potassium fertilizers is an important condition for obtaining high and stable crop yields. Plants provided with potassium become more resistant to excess and lack of moisture, high and low temperatures, their immunity to diseases and pests increases. Optimization of potassium nutrition contributes to improving the quality of grain, chemical composition and appearance of root crops, increasing the safety during transportation, provides strength and length of fiber bast culture, and as a result - increases the quality of marketable products [1].

The reserves of potassium-bearing minerals in the earth's crust are not unlimited, therefore the requirements for an integrated approach are an urgent task and have an important strategic importance, this concerns ore mining, enrichment, further processing, and also transportation and use.

\section{Materials and Methods}

Opening and developing the potash and salt deposits by mining method is always complicated by the presence of aquifers in the strata of rocks or water bodies on the surface within the limits of the mining territory. The main condition for the successful development of deposits is preventing the water channels between water bodies and mine workings. Ensuring this condition is achieved by matching the technology of the field development to geological and hydrogeological features.

One of the main hazards in the development of potash deposits is the constant threat of flooding. This topic should be given special attention and dwell in more detail, because from the preservation of the integrity of the waterproofing layer (hereinafter - WPL), the work of the entire mining enterprise as a whole depends.

The causes of flooding can be very diverse: both natural and man-made, caused by the flow of water into the mine workings. The penetration of aggressive waters occurs through rocks and various physical channels that exist both in natural conditions and appearing as a result of technogenic interference in the natural environment as a result of exploration, construction of mine structures and formation of excavation space. Current methods of forecasting, assessment and warning are based on the generalization of practical experience in the design and operation of mines and the development of mostly empirical criteria for assessing the probability of flooding of mines, taking into account the hydro-physical parameters of the water protection layer and the nature of the excavation space, taking into account the full range of parameters and methods of excavation. However, as the experience of mining industry shows, this does not always save it from miscalculations, which requires the further development of theoretical approaches to the consideration of this problem [2]. Existing (operating) rules for the protection of mines from flooding are based on the use of the concept and assessment of the zone of water-conducting cracks. 
There is no definition of the concept of "water-conducting cracks". As a rule, this means cracks, through which water enters. But water (brines) can enter the developed space in a literal sense along cracks that penetrate the water-protective thickness, having a definite cross-section, along faults, karsts, by pressing and usual filtration under hydrodynamic pressure. At present, the term "percolation" has found wide application in the scientific literature, which is often interpreted as filtration through porous materials, but these words are not synonyms. Percolation makes it possible to completely reinterpret the phenomenon of water penetration into the excavation space, to estimate the intensity of this manifestation and to determine the criteria of the WPL based on the geo-mechanical conditions of the rock massif. This term arose in the depths of physics and chemistry, as a process of infiltration in the form of a stochastic model of many physical processes. The seepage of brines in rocks can occur both under conditions of its natural state and during the disintegration of the rock massif into separate clusters. Disintegration of geological material occurs under the influence of loads on geological separations, which can be considered as clusters of a certain hierarchical level.

Consequently we can make two conclusions:

- to use the methods of fractal (cluster) analysis to estimate the likely flooding of the worked out space;

- to find the criteria for the flood situation.

The probability of formation of contracting (water-conducting) clusters is called percolation. This probability is the subject of research for water clusters and, ultimately, the assessment of probable flooding. An assessment of the WPL tension can be a criterion for the emergence of the danger of flooding. In order to assess the hydraulic permeability of rock integrity in complex geological conditions under various mining methods, it is obvious that geo-mechanical modeling of a mineral extraction facility is the most objective method not only in the initial period of mining, but also in the process. The experience of this approach to assessing the permeability of WPL is known in the literature. For reliable modeling and evaluation, it is necessary to have sufficient research and detailed geomechanical parameters of the rocks. Without going into the description of the modeling mechanism, it should be noted that the impermeability of WPL is determined by the acting stresses in the rock array.

It is considered canonical that the percolation of rocks is determined by the minimum principal stress, when it is exceeded the formation of discrete percolation paths (so-called water-conducting cracks) starts.

In order to maintain the integrity of the WPL (i.e. its waterproofness), the following criteria must be observed:

- the criterion of tensile stresses;

- the criterion of shear stresses (dilatancy test);

- the criterion of maximum principal stresses (criterion of hydraulic fracturing of a formation).

The numerical value of these criteria is established on the basis of experimental rocks tests.

However, these are not all the reasons for the emergency situation in mining enterprises. In the development of potash deposits, it is first of all necessary to take into account the specifics determined by the geological structure, salt properties (solubility) of the overlying rocks, the gas dynamic environment, the accumulation of potential energy of elastic compression leading to the rock outburst, and the choice of optimal and safe deposit development technology. In addition, the underdevelopment of deposits and the lack or inadequate monitoring of production processes that affect the movement of rocks and the geo-mechanical situation in the excavation districts entails emergency situations. 


\section{Results \& Discussion}

\subsection{Processing of potash, potassium-magnesium and salt deposits}

It is obvious that sylvinite ore extracted from the bowels of the earth is unfit for direct use, either as fertilizer or as a food product. First, it is necessary to select the necessary components, i.e. to enrich the ore. Enrichment of potassium ores began in the XIX century in Strasbourg by the method of thermal leaching with the subsequent crystallization of potassium salts from saturated salt solutions (processed using natural salts method).

Among the methods of enrichment the main place is currently occupied by flotation and galurgic.

The technological process of ore processing by the flotation method is based on the different ability of the sylvin and halite surfaces to be wetted with water, which is achieved by their treatment with surfactants (flotation agents) and subsequent isolation of the useful component into the foam [3-5].

Pink-red fine and granular potassium chloride is produced by flotation method. The mass fraction of $\mathrm{KCl}$ in the product is $95-96 \%$. The recovery of a useful component in the flotation method of processing is $85.5-87.2 \%$.

The workflow usually consists of the following stages (Figure 1):

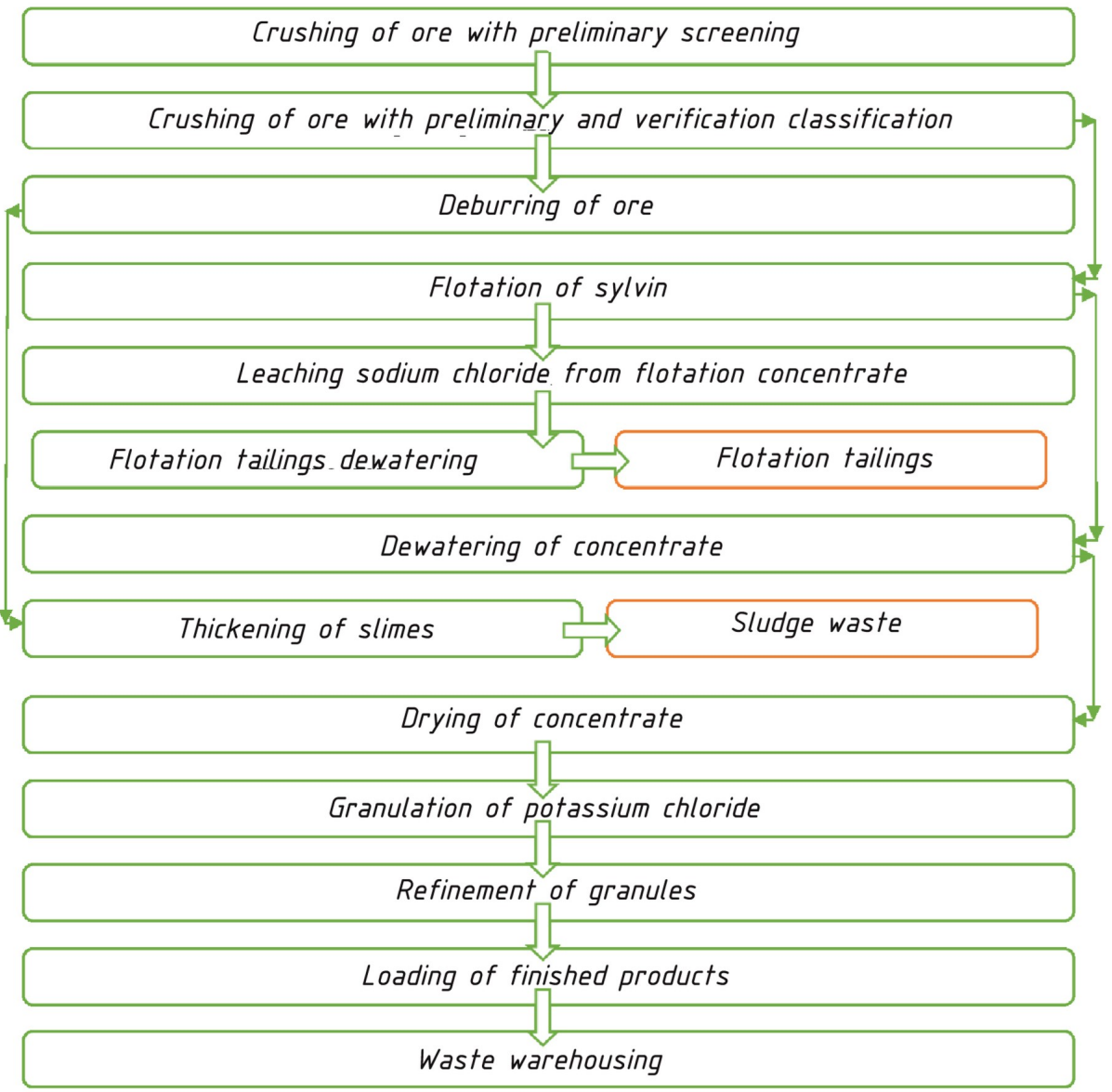

Fig. 1. The main technological stages of $\mathrm{KCl}$ production by flotation method. 


\subsection{The galurgical method}

The technological process of ore processing by the galurgical method is based on the physic-chemical features of the NaCl-KCl-H2O system. This method is based on a different dependence of the solubility of the constituent minerals - sylvin and halite - on the temperature: increased solubility of potassium chloride from the ore by a circulating solution at a temperature of $+115 \mathrm{C}$ and subsequent crystallization of the useful component upon cooling [6].

The white, crystalline, coarse-grained and granular potassium chloride is produced by the galurgical method. The large-crystal product (if necessary) can be painted pink-red. The mass fraction of $\mathrm{KCl}$ in the product is $96-99 \%$. The recovery of the useful component in the galurgical method of processing is $88-89 \%$.

At the moment, throughout the world, the flotation method predominates, because it is cheaper, and when using sylvin as a fertilizer, it does not matter whether the product contains $95-96 \%$ or $96-99 \% \mathrm{KCl}$ and what color it is.

However, the galurgic method has been used so far to produce a special-purpose product.

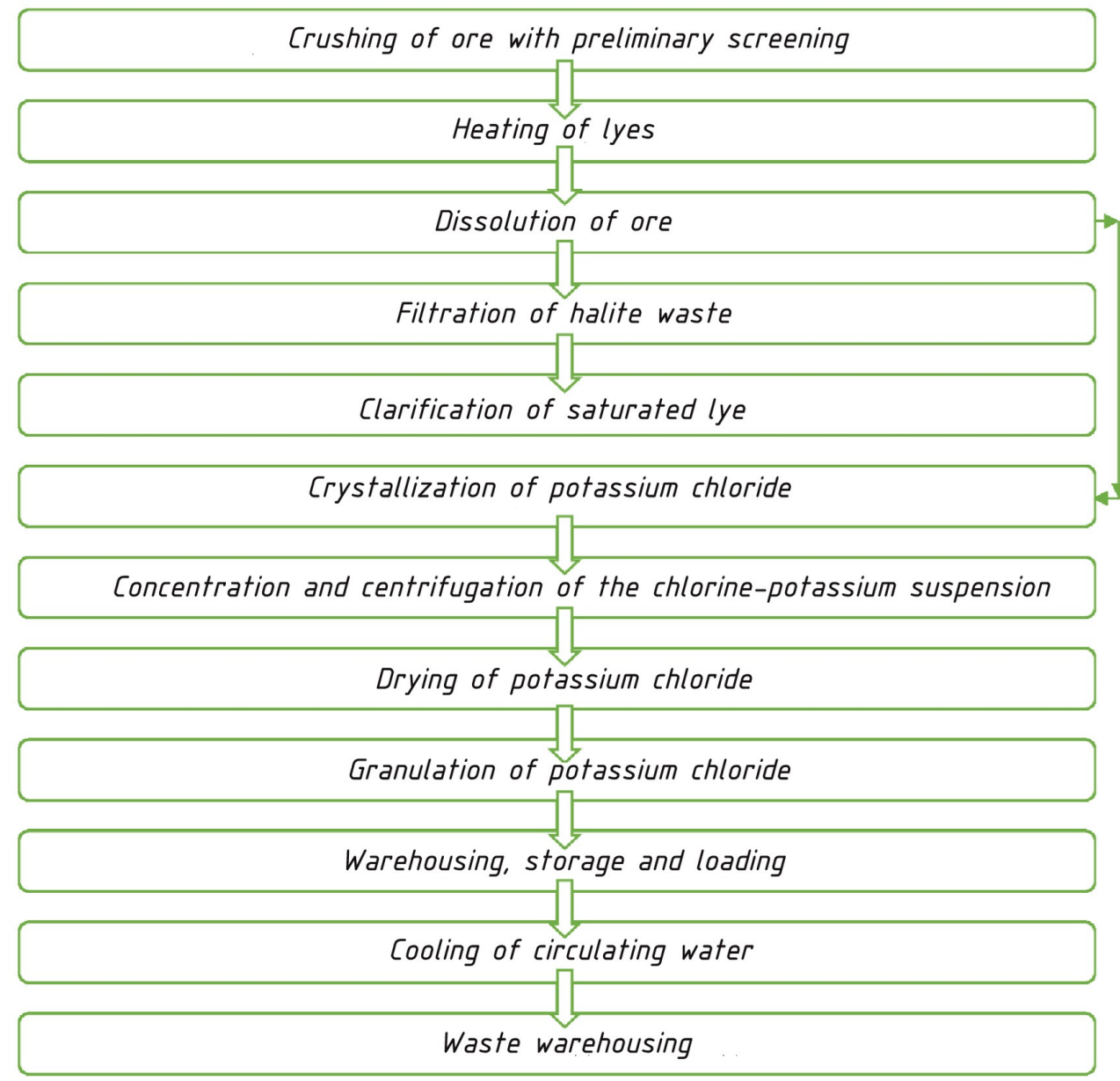

Fig. 2. The main technological stages of $\mathrm{KCl}$ production by galurgical method

An interesting alternative to flotation and galurgical methods of enrichment can be electrical separation. This method is little used in our country. However, it has many 
advantages over other methods. First, this method is "dry", i.e. without using water, which significantly increases environmental safety, saves water resources, the lack of which is already visible at the moment. Secondly, potash ores extracted from the bowels of the earth are dry, and in flotation and galurgic enrichment ("wet" methods) concentrate must be dried. So we first dry wet, and then dried again, which is obviously irrational. Thirdly, the process of electrical separation involves preliminary heating of the material, which at first glance is an additional expenditure of energy, but, as will be indicated below, it is most reasonable to ship the finished product in the form of granules, and the granulation of potassium chloride usually involves preheating. Fourthly, as already mentioned above, the reserves of potash and any other ores on Earth are limited and their rational and complex use is a very urgent task. The electric separation allows using ore in a complex way, because allows extracting from the ore sylvinite concentrate, which is used as raw material for fertilizer production, as well as halite concentrate, which can be used, for example, as a feed supplement.

Complex processing implies not only extraction, production with the maximum full extraction of a useful component, but also further use with minimal losses. Therefore, the concentrate produced is usually granulated, which, first, significantly reduces losses during transportation, and as a whole, plants had much better assimilate the granular product, because dissolves at the optimum speed.

The following processes are carried out in the granulation section: the classification of the dry concentrate coming from the drying process on the screens, followed by the finishing of the oversize product; pressing of potassium chloride concentrate in the compactor; crushing of the pressed concentrate; separation (classification) of the crushed concentrate on the screens with the crushing of the coarse fraction $((+4-0) \mathrm{mm})$ and the return of the fine fraction $((-2+0) \mathrm{mm})$ to the compactor supply conveyor; transportation of a granulation class of a grain size $(-4+2) \mathrm{mm}$ into a section of additional processing (refining); mechanical treatment of granules of potassium chloride concentrate in an abrasive mixer and then returning the fine fraction to the compacting obtained after screening on the screen; wetting of the granulate in the mixer, drying and cooling in the fluidized bed drier-cooler; treatment of the cooled granulate with reagents (oil / amine) followed by transportation to the warehouse of the finished product; air cleaning from dust in bag filters [1]. The separation of the granulation is rationally placed directly near the drying section in order to reduce the heat loss during transportation of the hot potassium chloride concentrate (since for normal operation of the pressing process the material entering the granulation must have a temperature of at least $120-130^{\circ} \mathrm{C}$ ).

\section{Conclusion}

All mentioned above, despite the need and feasibility of a differentiated solution, is a complex problem - the problem of ensuring the safe and efficient development of potash deposits by an underground method, in which they are combined as a single whole, requiring in all cases to take into account specific properties of salt rocks and the array.

All that suggests that it is time to start developing new rules for the safe development of potash, potassium-magnesium and salt deposits, which consist of two sections: the general theoretical part (in which international and domestic experience in the development of such deposits are collected, as well as rules and norms collected in order No. 599 of Rostechnadzor) and a special one, individually drafted for the development of the definite field.

The special part should be compiled in the following form: three basic instructions (on fixing mine workings on the field, on the applied field development systems, on flood prevention), which will be developed by accredited specialized organizations. The 
application of the instruction will be mandatory for all enterprises and organizations whose activities are related to the development of potash and salt deposits, as well as for design and other institutions and organizations, regardless of departmental subordination, ownership and economic activities, directly or indirectly related to the operation of mining enterprises.

In order to achieve this goal, it is necessary to create a monitoring and control committee under the Ministry of Natural Resources of the Russian Federation in the field of development of potash, potash, magnesium and salt deposits and to impose it with the task of controlling body in the mining industry in relation to the mining chemical industry and in the accreditation of specialized organizations for implementation of industry guidelines.

The main methods of processing ores of potassium, potassium-magnesium and salt deposits are currently flotation and galurgic. But, an interesting alternative is electrical separation, which allows processing potassium-containing raw materials more rationally and comprehensively.

\section{References}

1. S. N. Titkov, A. I. Mamedov, E. I. Soloviev, Enrichment of potash ores (Nedra, Moscow, 1982)

2. M. N. Kruk, A. S. Semenov, Journal of industrial pollution control, 33:1, 1024 (2017)

3. V. A. Glembotsky, V. I. Klassen, Flotation methods of enrichment (Nedra, Moscow, 1981)

4. L. N. Kirichenko, R. H. Sabirov, L. Y. Skvirsky, N. N. Teterina, Technology of flotation enrichment of potash ores (PSU, Perm, 2002)

5. V. B. Kuskov, Ya. V. Kuskova, V. L. Trushko, Mineral Processing, 1, 25 (2014)

6. S. N. Titkov, T. M. Gurkova, N. N. Panteleeva, A. Yu. Bondareva, A. V. Konobeevskykh, New Technologies of Potassium Ores Enrichment (TPU, Tomsk, 2013) 